\title{
Prospective IncRNA-miRNA-mRNA regulatory network of long non-coding RNA LINC00968 in non-small cell lung cancer A549 cells: A miRNA microarray and bioinformatics investigation
}

\author{
DONG-YAO LI ${ }^{1 *}$, WEN-JIE CHEN ${ }^{1 *}$, LEI LUO $^{1}$, YONG-KUN WANG ${ }^{1}$, JUN SHANG $^{1}$, \\ YU ZHANG ${ }^{2}$, GANG CHEN ${ }^{2}$ and SHI-KANG $\mathrm{LI}^{1}$ \\ Departments of ${ }^{1}$ Thoracic and Cardiovascular Surgery and ${ }^{2}$ Pathology, The First Affiliated Hospital of \\ Guangxi Medical University, Nanning, Guangxi 530021, P.R. China
}

Received December 12, 2016; Accepted October 5, 2017

DOI: 10.3892/ijmm.2017.3187

\begin{abstract}
Accumulating evidence suggests that the dysregulation of long non-coding RNAs (lncRNAs) serves vital roles in the incidence and progression of lung cancer. However, the molecular mechanisms of LINC00968, a recently identified lncRNA, remain unknown. The objective of present study was to investigate the role of a prospective lncRNA-miRNA-mRNA network regulated by LINC00968 in non-small cell lung cancer cells. Following the transfection of lentiviruses carrying LINC00968 into A549 cells, the microRNA (miRNA) expression profile of the cells in response to the overexpression of LINC00968 was detected using an miRNA microarray. Five differentially expressed miRNAs (DEMs) with LINC00968 overexpression were obtained, including miR-9-3p, miR-22-5p, miR-668-3p, miR-3675-3p and miR-4536-3p. Five target prediction algorithms and three target validation algorithms were used to obtain 1,888 prospective target genes of the five DEMs. The result of Gene Ontology analysis suggested that these five DEMs were involved in complex cellular pathways, which included intracellular transport, organelle lumen and nucleotide binding. Furthermore, analysis of Kyoto Encyclopedia of Genes and Genomes pathways indicated that the five DEMs were important regulators in the adherens junction and focal
\end{abstract}

Correspondence to: Professor Shi-Kang Li, Department of Thoracic and Cardiovascular Surgery, The First Affiliated Hospital of Guangxi Medical University, 6 Shuangyong Road, Nanning, Guangxi Zhuang Autonomous Region 530021, P.R. China

E-mail: shikangli@hotmail.com

Professor Gang Chen, Department of Pathology, The First Affiliated Hospital of Guangxi Medical University, 6 Shuangyong Road, Nanning, Guangxi Zhuang Autonomous Region 530021, P.R. China E-mail: chen_gang_triones@163.com

*Contributed equally

Key words: lung cancer, LINC00968, miRNA microarray, IncRNA-miRNA-mRNA, protein-protein interaction, the Cancer Genome Atlas adhesion. An lncRNA-miRNA-mRNA regulatory network and a protein-protein interaction network were then constructed. Eventually, a prospective IncRNA-miRNA-mRNA regulatory network of LINC00968, three miRNAs (miR-9, miR-22 and miR-4536) and two genes (polo-like kinase 1 and exportin-1) was obtained following validation in the Cancer Genome Atlas database. These results may provide novel insights to support future research into lncRNA in lung cancer.

\section{Introduction}

Lung cancer results in the death of $\sim 1.59$ million individuals worldwide each year, and is a leading cause of cancer mortality $(1,2)$. According to the pathological diagnostic classification, non-small cell lung cancer (NSCLC) accounts for $>85 \%$ of cases of lung cancer (3). The molecular pathogenesis of NSCLC has received increasing attention in recent years (4-7). Thus, non-coding RNAs, which serve crucial functions in numerous biological processes have become of interest. Based on their size, sequence and function, non-coding RNAs can be classified into various subclasses, the two most notable of which are long-noncoding RNAs (lncRNAs) and microRNAs (miRNAs).

LncRNAs are parts of non-coding RNAs with $>200$ nucleotides and do not encode proteins (8). Previous studies have indicated that lncRNAs may have an important involvement in cancer biology and cellular processes $(9,10)$. LncRNAs may contribute to these processes via various mechanisms at the post-transcriptional level, for example, by serving as precursors to miRNA and regulating mRNA by interacting with miRNAs $(11,12)$. Unlike lncRNAs, miRNAs are generally 18-25 nucleotides in length, and are small non-coding protein RNAs that are able to bind to the 3' untranslated region of target mRNAs and result in the degradation and translational downregulation of target mRNAs $(13,14)$. In addition, miRNAs have the ability to regulate the coding and noncoding transcriptome.

It is worthy of note that lncRNAs and miRNAs serve pivotal roles in numerous similar processes, including cell proliferation, apoptosis and carcinogenesis. Due to the similarity of their functions, it may be hypothesized that an interaction between lncRNAs and miRNAs occurs during the tumorigenic process. For instance, the competing endogenous RNA (ceRNA) 
hypothesis that IncRNAs serve as molecular sponges for miRNAs has been proposed $(15,16)$. Thus, the discovery of IncRNA-miRNA-mRNA networks may lead to a more comprehensive understanding of the etiology and metastasis mechanism of cancer and to potential therapeutic targets, and such networks been studied for several types of cancer $(17,18)$.

In a previous study, the present authors identified $47 \mathrm{lncRNAs}$, including LINC00968, that were differentially expressed between normal lung tissues and tumor samples by bioinformatic analysis (19). Furthermore, a significant downregulation of LINC00968 in lung adenocarcinoma (LUAD) tissues and A549 cells was discovered (data not shown). These experiments suggest that LINC00968 may serve important roles in lung cancer progression. In the present study, using miRNA profiling by microarray following the overexpression of LINC00968 in A549 cells, Gene Ontology (GO) and Kyoto Encyclopedia of Genes and Genomes (KEGG) pathway analyses of the differentially expressed miRNAs (DEMs) were performed.Furthermore, a prospective IncRNA-miRNA-mRNA regulatory network of LINC00968 was constructed. These results may assist in the exploration of the underlying regulatory mechanisms in the progression of lung cancer.

\section{Materials and methods}

Overexpression of LINC00968 in A549 cells. A549 cells were obtained from the Cell Bank of the Chinese Academy of Sciences (Shanghai, China). Following culture in 6-well plates overnight, the cells $\left(2 \times 10^{6}\right)$ were transfected with a solution of lentiviruses in F-12 culture medium containing $10 \%$ serum (Gibco, Grand Island, NY, USA), $100 \mathrm{U} / \mathrm{ml}$ penicillin and $100 \mu \mathrm{g} / \mathrm{ml}$ streptomycin (Hyclone, Logan, UT, USA) for $24 \mathrm{~h}$. The solution was then removed, fresh F-12 culture medium was added and the A549 cells were incubated for another 24-72 h. The conventional culture environment was $5 \% \mathrm{CO}_{2}$ air in a humidified incubator at $37^{\circ} \mathrm{C}$. Lentiviruses encoding LINC00968 were designed and synthesized by Shanghai GenePharma Co., Ltd. (Shanghai, China). An inverted fluorescence microscope was applied to examine the transfection efficiency (data not shown).

RNA isolation and miRNA microarray detection. The sample analysis and microarray hybridization were conducted by KangChen Bio-tech (Shanghai, China). Total RNA was isolated using TRIzol (Invitrogen; Thermo Fisher Scientific, Inc., Waltham, MA, USA) and purified using an RNeasy mini kit (Qiagen, Inc., Valencia, CA, USA) according to the manufacturer's protocol. The quality and quantity of DNA was monitored using a NanoDrop spectrophotometer (ND-2000; Thermo Fisher Scientific, Inc.) followed by gel electrophoresis to determine the integrity of the RNA. The miRNA was labeled using a miRCURY ${ }^{\mathrm{TM}} \mathrm{Hy} 3^{\mathrm{TM}} / \mathrm{Hy} 5^{\mathrm{TM}}$ Power labeling kit and hybridized with the miRCURY' ${ }^{\mathrm{TM}}$ LNA array (version 18.0) (both from Exiqon A/S, Vedbaek, Denmark). The slides were then scanned with the Axon GenePix 4000B microarray scanner and the scanned images were analyzed using GenePix Pro 6.0 software (both from Molecular Devices, LLC, Sunnyvale, CA, USA). DEMs were identified according to fold changes and $\mathrm{P}$-value at the threshold set of $\log _{2} \mathrm{FCl}>0.58$ and $\mathrm{P}<0.05$.
Target gene prediction of DEMs. In order to determine the potential association between mRNAs and miRNAs, the potential transcriptional targets of the DEMs were predicted using five miRNA target prediction algorithms: miRTarBase (http://mirtarbase.mbc.nctu.edu.tw/), miRDB (http://www. mirdb.org/), GeneCards (http://www.genecards. org), TargetScan (http://www.Targetscan.org/) and RNA22 (https://cm.Jefferson.edu/rna22/). Target genes that were commonly predicted by at least three of these algorithms were considered predicted target genes. Validated target genes verified by experiments were obtained from miRecords (http://c1.accurascience.com/miRecords/), miRTarBase and TarBase (http://diana.imis.athenainnovation.gr/DianaTools/ index.php? $\mathrm{r}=$ tarbase/index). Target genes from any one of these three algorithms were listed as validated target genes.

GO and KEGG pathway analysis. Functional enrichment analysis is essential to uncover biological functions of miRNA target genes. To gain an understanding of the biological functions of miRNA target genes, GO classification and KEGG pathway enrichment analysis were performed using the bioinformatics software DAVID 6.7 (https://david-ncifcrf.gov/). GO classifies genes according to three categories, biological process, molecular function and cellular component, and presents a common descriptive framework of gene annotation and classification for the analysis of gene-set data. In addition, the potential involvement in biological pathways of the DEMs were detected based on analysis using the KEGG pathway database, which is a credible and informative database that includes almost all biological signal pathways (20). The false discovery rate (FDR) $<0.05$ was set as the cut-off for selecting significantly enriched KEGG pathways.

Construction of a network of IncRNA-miRNA-mRNA and protein-protein interaction (PPI). Following the integration of the results of the predicted targets and validated targets, prospective targets of the DEMs were obtained. In order to demonstrate the association among lncRNAs, miRNAs and mRNAs, an lncRNA-miRNA-mRNA interaction network was created. The network was visualized using Cytoscape (version 3.4.0) (21). The online tool STRING (http://string-db. org/) was then used to draw a PPI network of the prospective targets. The highest confidence of 0.9 was selected as the minimum required interaction score.

Extraction of gene and miRNA expression profiles from the Cancer Genome Atlas (TCGA). A download of RNA-seq data and miRNA-seq data of lung cancer from the TCGA (https:// cancergenome.nih.gov/) data portal was conducted, in which the extracted expression data included LINC00968, DEMs and mRNAs associated with LINC00968.

Statistical analysis. Statistical analyses were performed with SPSS software version 22.0 (IBM Corp., Armonk, NY, USA). The mean \pm standard deviation was used to present the experimental results. A two-tailed t-test was used to assess the differences between the different groups. The correlation among lncRNAs, miRNAs and mRNAs was analyzed by Pearson's correlation analysis. A statistically significant threshold was defined as $\mathrm{P}<0.05$. 


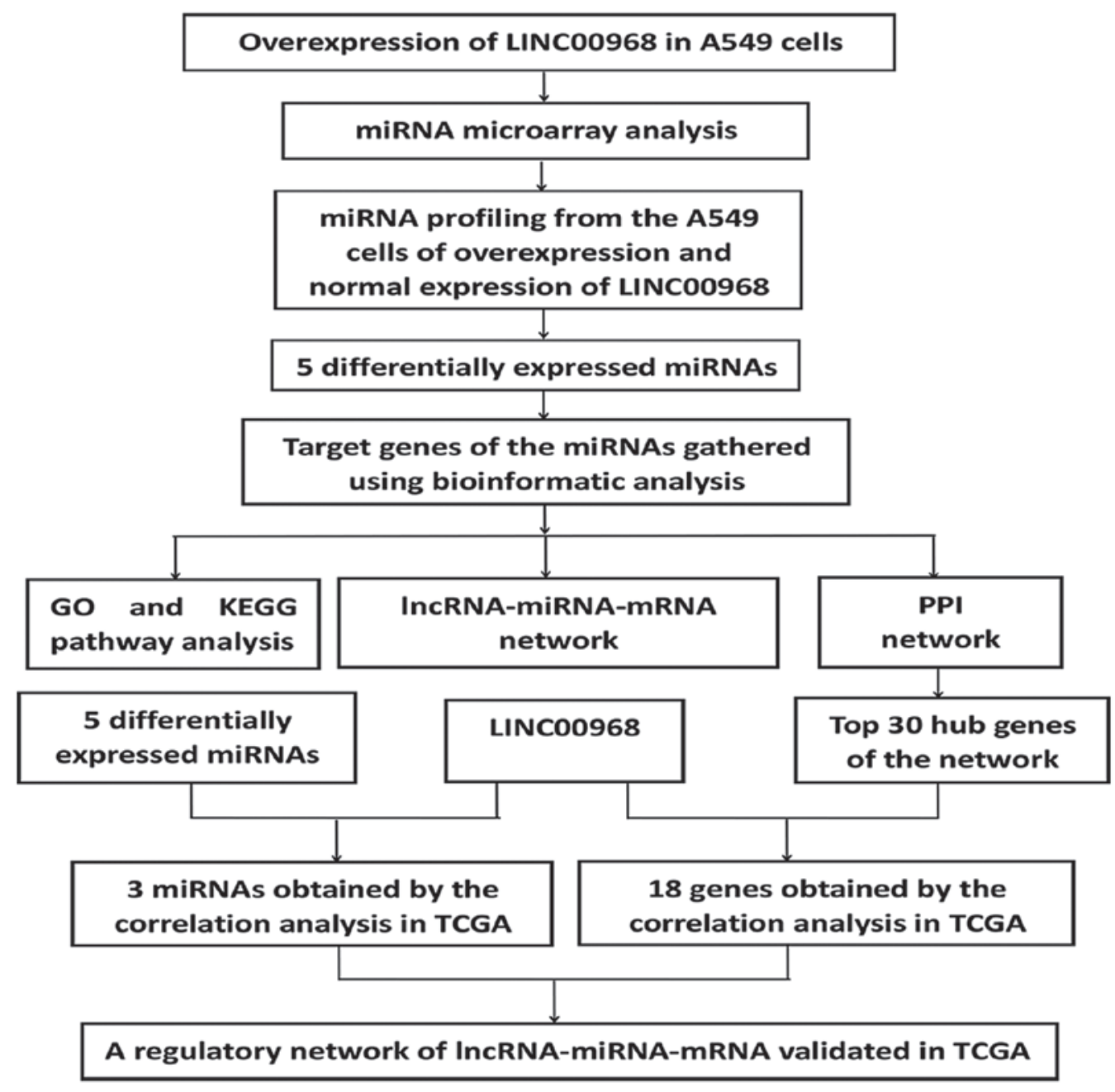

Figure 1. Flowchart of the present study. GO, Gene Ontology; KEGG, Kyoto Encyclopedia of Genes and Genomes; TCGA, The Cancer Genome Atlas; miRNA, microRNA; lncRNA, long non-coding RNA; mRNA, messenger RNA.

Table I. Summary of differentially expressed miRNAs detected by microarray analysis.

ID Name Fold change P-value

Upregulated

miRNA

148214

$\operatorname{miR}-3675-3 p$

2.034

0.031

Downregulated miRNA

$\begin{array}{llll}145701 & \text { miR-668-3p } & 0.513 & 0.031 \\ 168616 & \text { miR-4536-3p } & 0.483 & 0.035 \\ 42532 & \text { miR-22-5p } & 0.559 & 0.015 \\ 29852 & \text { miR-9-3p } & 0.569 & 0.044\end{array}$

\section{Results}

miRNA profiling following the overexpression of LINC00968. An experimental flow chart of the study is shown in Fig. 1. To uncover the association between LINC00968 and miRNAs in lung cancer, microarray expression profiling of miRNAs in
A549 cells transfected with LINC00968 was performed. In the microarray analysis, 166 miRNAs were detected, of which 75 were upregulated and 91 downregulated. Among these, five DEMs were identified, of which miR-3675 was highly expressed, and four miRNAs (miR-9, miR-22, miR-668 and miR-4536) exhibited low expression in A549 cells (Table I), suggesting that these DEMs were associated with LINC00968 in lung cancer cells. Additionally, the expression profile of the five DEMs is shown in a heatmap and volcano plot (Fig. 2). The DEMs were then subjected to further analysis.

Collection of prospective target genes of DEMs via bioinformatic approaches. Given that the biological significance of DEMs depends on their effect upon their targets, the predicted target genes of the five DEMs were identified. Using this approach, 552 predicted target genes were obtained three times in the five software programs. In addition, 1,609 validated target genes with experimental validation were collected from the miRTarBase, TarBase and miRecords databases. Lastly, 1,888 prospective target genes were identified by integrating the results of the predicted target genes and validated target genes (Fig. 3).

GO classification and KEGG pathways of miRNA prospective target genes. The 1,888 prospective target genes of five DEMs 

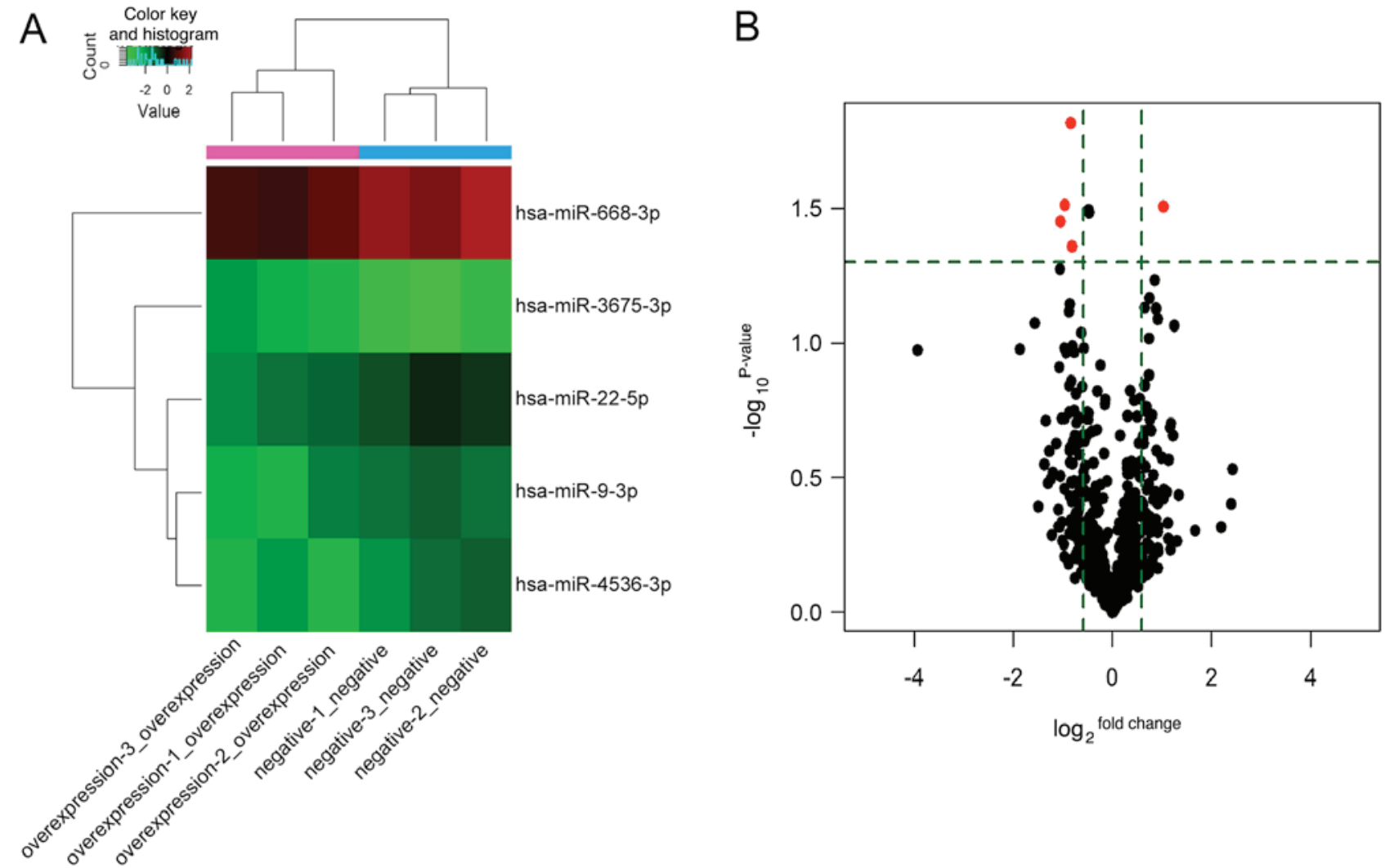

Figure 2. Differentially expressed miRNAs (DEMs) associated with LINC00968. (A) Hierarchical cluster analysis of DEMs following LINC00968 overexpression in A549 cells. Red indicates high expression and green indicates low expression. (B) Volcano plot for five DEMs following LINC00968 overexpression in A549 cells. Red represents miRNAs with a statistically significant difference in expression, and black represents miRNAs with no significant difference. miRNA, microRNA; DEM, differentially expressed miRNA.

were then subjected to GO analysis. Through GO annotation and enrichment analysis, the roles of gene products from biological process, cellular component and molecular function were identified (Table II). The most significant term in biological process was intracellular transport (GO:0046907, $\mathrm{P}=9.75 \times 10^{-14}$ ), that in cellular component was organelle lumen (GO:0043233, $\mathrm{P}=3.96 \times 10^{-16}$ ) and that in molecular function was nucleotide binding (GO:0000166, $\mathrm{P}=2.76 \times 10^{-9}$ ). To better represent gene enrichment in the three major categories, a pathway schematic was constructed consisting of the top 30 enriched GO terms (Fig. 4). In the KEGG analysis, four significantly enriched pathways (FDR $<0.05)$ were obtained (Table III), including adherens junction, focal adhesion, long-term potentiation and renal cell carcinoma, among which the two most significant pathways were adherens junction $\left(\mathrm{P}=3.13 \times 10^{-7}\right)$ and focal adhesion $\left(\mathrm{P}=6.90 \times 10^{-7}\right)$.

Regulatory network of lncRNA-miRNA-mRNA. To identify the potential links among LINC00968, DEMs and mRNAs, miRNA microarray and bioinformatic analyses were performed. Consequently, five DEMs were detected via the overexpression of LINC00968, which provided the five IncRNA-miRNA interactions. In addition, to obtain the prospective target genes, the results of predicted targets and validated targets were integrated, and the miRNA-mRNA interactions were subsequently obtained. By combining the IncRNA-miRNA and miRNA-mRNA interactions, an lncRNA-miRNA-mRNA network was constructed and visualized with Cytoscape (Fig. 5A). The network revealed a preliminary connection between LINC00968, the five DEMs miR-9-3p, miR-22-5p, miR-668-3p, miR-3675-3p and miR-4536-3p, and 1,888 prospective target genes, which required further verification.

PPI network of 1,888 prospective target genes. To identify the association between target genes, a PPI network was generated using STRING that presented the strength of the links of different genes. In the PPI network analysis of the prospective targets, the top 30 genes among all hub genes were identified, on the basis of the connectivity between genes (Fig. 5B). These top 30 genes may have tight connections to the lncRNA-miRNA-mRNA network. Furthermore, the number of links to each of the top 30 genes was calculated, of which UBA52 was the gene with the highest connectivity in the top 30 genes (Fig. 6).

Validation of the correlation among LINC00968, DEMs and hub genes in the TCGA database. The correlation among LINC00968, DEMs and hub genes was evaluated by bivariate correlation analysis from the aforementioned lncRNA-miRNA-mRNA network in LUAD patients based upon TCGA data. Three DEMs were significantly correlated with LINC00968 in TCGA, and the results suggested that miR-9 and miR-22 were negatively correlated with LINC00968 and miR-4536 was positively correlated with LINC00968 in LUAD patients (Fig. 7A-a-f). In addition, 18 hub genes of the 
Table II. Top five enriched GO terms of prospective target genes from three GO categories.

\begin{tabular}{|c|c|c|c|c|c|}
\hline GO ID & GO Term & P-value & FDR & Count & Genes \\
\hline \multicolumn{6}{|c|}{ Biological process } \\
\hline GO:0046907 & Intracellular transport & $9.75 \times 10^{-14}$ & $1.80 \times 10^{-10}$ & 132 & $\begin{array}{l}\text { NCBP2, GRPEL2, XPO1, } \\
\text { GRPEL1, SEC31A, LTBP2, AP1G2, } \\
\text { TGFB2, HOOK1, CRY2 }\end{array}$ \\
\hline GO:0008104 & Protein localization & $5.59 \times 10^{-12}$ & $1.03 \times 10^{-8}$ & 158 & $\begin{array}{l}\text { GRPEL2, XPO1, GRPEL1, SEC31A, } \\
\text { LTBP2, AP1G2, CHMP4B, MXI1, } \\
\text { VPS33A, CTNNB1 }\end{array}$ \\
\hline GO:0045184 & $\begin{array}{l}\text { Establishment of protein } \\
\text { localization }\end{array}$ & $6.89 \times 10^{-11}$ & $1.27 \times 10^{-7}$ & 139 & $\begin{array}{l}\text { GRPEL2, XPO1, GRPEL1, SEC31A, } \\
\text { LTBP2, AP1G2, CHMP4B, VPS33A, } \\
\text { TGFB2, HOOK1 }\end{array}$ \\
\hline GO:0015031 & Protein transport & $7.01 \times 10^{-11}$ & $1.30 \times 10^{-7}$ & 138 & $\begin{array}{l}\text { GRPEL2, XPO1, GRPEL1, SEC31A, } \\
\text { LTBP2, AP1G2, CHMP4B, VPS33A, } \\
\text { TGFB2, HOOK1 }\end{array}$ \\
\hline GO:0070727 & $\begin{array}{l}\text { Cellular macromolecule } \\
\text { localization }\end{array}$ & $1.05 \times 10^{-10}$ & $1.94 \times 10^{-7}$ & 88 & $\begin{array}{l}\text { GRPEL2, COPA, XPO1, GRPEL1, } \\
\text { SEC24A, LTBP2, AP1G2, } \\
\text { AP1B1, FGF9, CLTC }\end{array}$ \\
\hline \multicolumn{6}{|c|}{ Cellular component } \\
\hline GO:0043233 & Organelle lumen & $3.96 \times 10^{-16}$ & $6.66 \times 10^{-13}$ & 281 & $\begin{array}{l}\text { XRCC5, PDP1, MEF2C, MRPL40, } \\
\text { PNMA3, PDP2, NAA15, SYNCRIP, } \\
\text { INTS2, CDC16 }\end{array}$ \\
\hline GO:0031974 & $\begin{array}{l}\text { Membrane-enclosed } \\
\text { lumen }\end{array}$ & $4.28 \times 10^{-16}$ & $6.66 \times 10^{-13}$ & 285 & $\begin{array}{l}\text { XRCC5, PDP1, MEF2C, MRPL40, } \\
\text { PNMA3, PDP2, NAA15, SYNCRIP, } \\
\text { INTS2, CDC16 }\end{array}$ \\
\hline GO:0070013 & $\begin{array}{l}\text { Intracellular organelle } \\
\text { lumen }\end{array}$ & $7.94 \times 10^{-16}$ & $1.15 \times 10^{-12}$ & 275 & $\begin{array}{l}\text { XRCC5, MEF2C, PDP1, MRPL40, } \\
\text { PNMA3, PDP2, NAA15, SYNCRIP, } \\
\text { INTS2, CDC16 }\end{array}$ \\
\hline GO:0031981 & Nuclear lumen & $1.71 \times 10^{-15}$ & $2.48 \times 10^{-12}$ & 234 & $\begin{array}{l}\text { MEF2C, XRCC5, PNMA3, NAA15, } \\
\text { SYNCRIP, INTS2, CDC16, SART3, } \\
\text { WTAP, CD2AP }\end{array}$ \\
\hline GO:0043228 & $\begin{array}{l}\text { Non-membrane-bounded } \\
\text { organelle }\end{array}$ & $2.50 \times 10^{-14}$ & $3.72 \times 10^{-11}$ & 363 & $\begin{array}{l}\text { XRCC5, MRPL40, KIFC1, PNMA3, } \\
\text { UTRN, CDC16, CCT3, MYLIP, } \\
\text { REST, WTAP }\end{array}$ \\
\hline \multicolumn{6}{|c|}{ Molecular function } \\
\hline GO:0000166 & Nucleotide binding & $2.76 \times 10^{-9}$ & $4.45 \times 10^{-6}$ & 320 & $\begin{array}{l}\text { XRCC5, LDHB, KIFC1, ADCY7, } \\
\text { U2AF2, SYNCRIP, LEMD3, CCT3, } \\
\text { SART3, RNF213 }\end{array}$ \\
\hline GO:0005524 & ATP binding & $1.45 \times 10^{-7}$ & $2.34 \times 10^{-4}$ & 218 & $\begin{array}{l}\text { XRCC5, KIFC1, ADCY7, CCT3, } \\
\text { ACTG1, KIF13A, MAP3K7, WNK4, } \\
\text { DHX33, DHX36 }\end{array}$ \\
\hline GO:0032559 & $\begin{array}{l}\text { Adenyl-ribonucleotide } \\
\text { binding }\end{array}$ & $3.94 \times 10^{-7}$ & $6.37 \times 10^{-4}$ & 218 & $\begin{array}{l}\text { XRCC5, KIFC1, ADCY7, CCT3, } \\
\text { ACTG1, KIF13A, MAP3K7, WNK4, } \\
\text { DHX33, DHX36 }\end{array}$ \\
\hline GO:0032555 & $\begin{array}{l}\text { Purine ribonucleotide } \\
\text { binding }\end{array}$ & $5.89 \times 10^{-7}$ & $9.51 \times 10^{-4}$ & 258 & $\begin{array}{l}\text { XRCC5, KIFC1, ADCY7, CCT3, } \\
\text { MAP3K7, ACTG1, KIF13A, WNK4, } \\
\text { RAB23, DHX33 }\end{array}$ \\
\hline GO:0032553 & $\begin{array}{l}\text { Ribonucleotide } \\
\text { binding }\end{array}$ & $5.89 \times 10^{-7}$ & $9.51 \times 10^{-4}$ & 258 & $\begin{array}{l}\text { XRCC5, KIFC1, ADCY7, CCT3, } \\
\text { MAP3K7, ACTG1, KIF13A, WNK4, } \\
\text { RAB23, DHX33 }\end{array}$ \\
\hline
\end{tabular}


Table III. Top four enriched KEGG pathways obtained after KEGG pathway analysis.

\begin{tabular}{|c|c|c|c|c|c|}
\hline KEGG ID & KEGG term & P-value & FDR & Count & Genes \\
\hline hsa04520 & $\begin{array}{l}\text { Adherens } \\
\text { junction }\end{array}$ & $3.13 \times 10^{-7}$ & $3.84 \times 10^{-4}$ & 26 & $\begin{array}{l}\text { PARD3, ERBB2, CTNND1, CDH1, SRC, IQGAP1, } \\
\text { CTNNB1, VCL, ACTG1, MAP3K7, CSNK2A2, IGF1R, } \\
\text { CDC42, SSX2IP, EGFR, PTPRM, PTPRF, TGFBR1, TGFBR2, } \\
\text { CREBBP, SMAD2, MAPK1, TJP1, EP300, FYN, MAPK3 }\end{array}$ \\
\hline hsa04510 & $\begin{array}{c}\text { Focal } \\
\text { adhesion }\end{array}$ & $6.90 \times 10^{-7}$ & $8.47 \times 10^{-4}$ & 47 & $\begin{array}{l}\text { CAV1, TLN1, GRB2, ERBB2, PIP5K1C, ELK1, ITGB1, PTEN, } \\
\text { SRC, VCL, CTNNB1, AKT1, ACTG1, CDC42, IGF1R, PAK4, } \\
\text { PPP1R12A, LAMB1, THBS1, THBS2, PIK3R1, SHC4, } \\
\text { FN1, PRKCA, EGFR, COL4A2, COL4A1, FLT1, MAP2K1, } \\
\text { BRAF, ROCK2, MYLK3, MYL12B, MAPK10, FLNC, FLNB, } \\
\text { MAPK1, FYN, ITGA5, JUN, MAPK3, RAP1A, MAPK9, } \\
\text { RAP1B, COL1A1, CRK, MYLK }\end{array}$ \\
\hline hsa04720 & $\begin{array}{l}\text { Long-term } \\
\text { potentiation }\end{array}$ & $2.54 \times 10^{-5}$ & $3.12 \times 10^{-2}$ & 21 & $\begin{array}{l}\text { PRKCA, MAP2K1, BRAF, CREBBP, PPP3R1, ITPR3, } \\
\text { MAPK1, NRAS, RPS6KA3, EP300, RPS6KA2, } \\
\text { MAPK3, PPP3CB, PPP1R12A, RAP1A, RAP1B, } \\
\text { PRKACA, PPP3CA, PRKACB, PLCB1, PLCB2 }\end{array}$ \\
\hline hsa05211 & $\begin{array}{l}\text { Renal cell } \\
\text { carcinoma }\end{array}$ & $4.05 \times 10^{-5}$ & $4.97 \times 10^{-2}$ & 21 & $\begin{array}{l}\text { MAP2K1, EPAS1, BRAF, GRB2, CREBBP, EGLN1, } \\
\text { ARNT, TGFB2, AKT1, CDC42, MAPK1, NRAS, EP300, } \\
\text { HIF1A, JUN, PAK4, MAPK3, RAP1A, RAP1B, CRK, PIK3R1 }\end{array}$ \\
\hline
\end{tabular}

KEGG, Kyoto Encyclopedia of Genes and Genomes; FDR, false discovery rate.

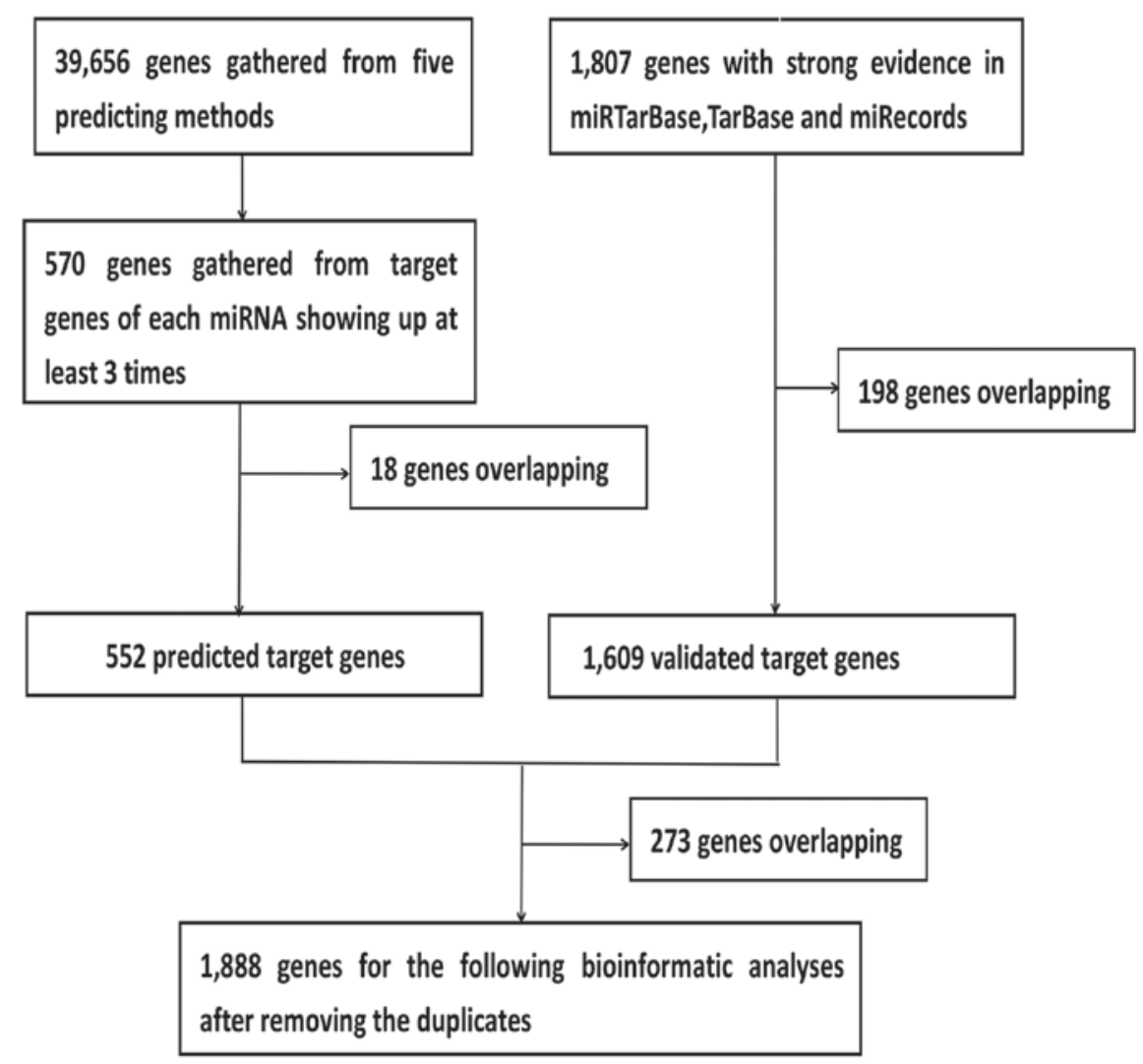

Figure 3. Flowchart of bioinformatic analysis of the propective targets of five differentially expressed miRNAs. miRNA, microRNA

top 30 genes were identified as being significantly correlated with LINC00968 in LUAD based upon TCGA $(\mathrm{P}<0.05)$. The correlation between the three miRNAs and the 18 hub genes was then analyzed (Table IV). Polo-like kinase 1 (PLKI) and 


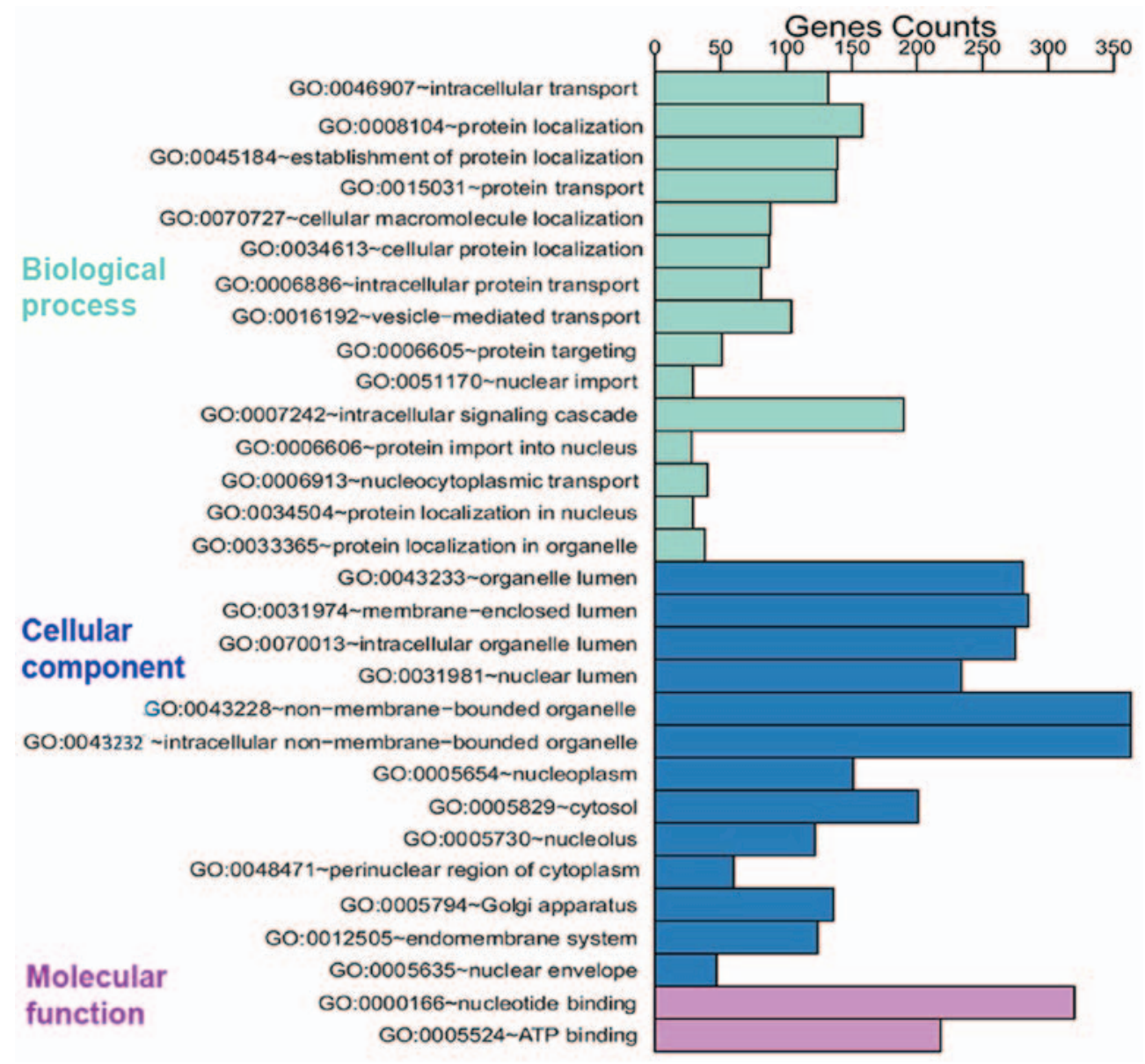

Figure 4. Enrichment of GO terms. The top 30 enriched GO terms from the GO analysis in the three categories of biological process, cellular component and molecular function. GO, Gene Ontology.

Table IV. Genes associated with the three differentially expressed miRNAs that have a significant association with LINC00968 in the 18 hub genes based on the TCGA database.

\begin{tabular}{ll}
\hline miRNA & \multicolumn{1}{c}{ Associated genes } \\
\hline miR-9-1 & JUN, PLK1, FYN, PIK3R1, NCBP2, XPO1, \\
PABPC1, NOTCH1 \\
miR-9-2 & JUN, PLK1, FYN, PIK3R1, NCBP2, XPO1, \\
& PABPC1, NOTCH1 \\
miR-9-3 & JUN, PLK1, FYN, PIK3R1, NCBP2, XPO1, \\
& PABPC1, NOTCH1 \\
miR-22 & SRC, HSP90AA1, CDC42, PLK1, FYN, \\
& NCBP2, XPO1, PABPC1, YWHAG \\
miR-4536-1 & SRC, HSP90AA1, PLK1, PIK3R1, XPO1, \\
& NOTCH1, YWHAG \\
miR-4536-2 & SRC, PLK1, PIK3R1, NCBP2, XPO1, \\
& NOTCH1, PTEN, YWHAG
\end{tabular}

TCGA, The Cancer Genome Atlas; miRNA, microRNA.

exportin-1 (XPO1) were found to be co-associated with miR-9, miR-22 and miR-4536 (Fig. 7A-g-1 and B-a-f). Furthermore, an lncRNA-miRNA-mRNA network of LINC00968 was validated in LUAD patients based on the TCGA dataset by combining correlations between LINC00968 and the co-associated genes (Fig. 7B-g-h), which included the three miRNAs (miR-9, miR-22 and miR-4536) and two hub genes (PLK1 and XPO1). Finally, these data suggested that LINC00968 implemented its biofunction in LUAD patients by directly or indirectly targeting PLK1 and XPO1 (Fig. 8).

\section{Discussion}

As described in a previous study by the present research team, 47 differentially expressed lncR NAs were discovered in tumor tissues and normal lung tissues based on gene expression files from five GEO datasets, one of which was LINC00968 (19). In addition, the downregulation of LINC00968 expression was found in LUAD tissues and A549 cells, suggesting its potential tumor suppressor role in LUAD. Therefore, the biological mechanisms of LINC00968 in LUAD patients were explored by lncRNA-miRNA-mRNA network and bioinformatic analysis in the present study.

To date, IncRNAs and miRNAs are known to function as key regulators in the biological processes of numerous cancers and may have good diagnostic and prognostic values for a variety of cancers, including lung cancer (22). Moreover, accumulating evidence indicates that lncRNAs are capable of binding specific miRNAs and regulating their function. 

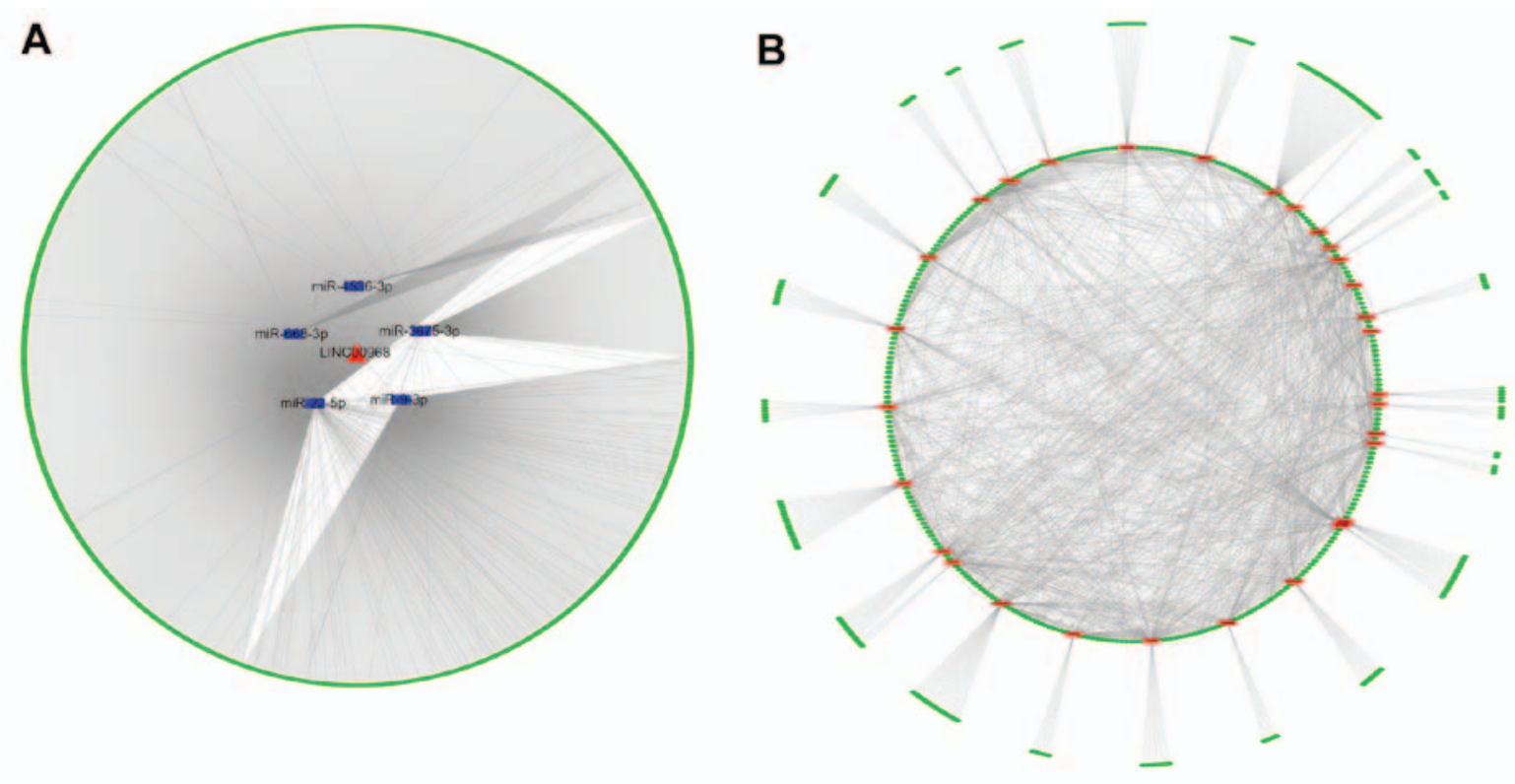

Figure 5. Interaction network by bioinformatic analysis. (A) The lncRNA-miRNA-mRNA network. Red triangle represents lncRNA, blue rectangles represent miRNAs, and green ellipses represent mRNAs. (B) Protein-protein interaction network of the top 30 hub genes. Red ellipses represent the top 30 genes, and green ellipses represent genes associated with the 30 genes. miRNA, microRNA; lncRNA, long non-coding RNA.

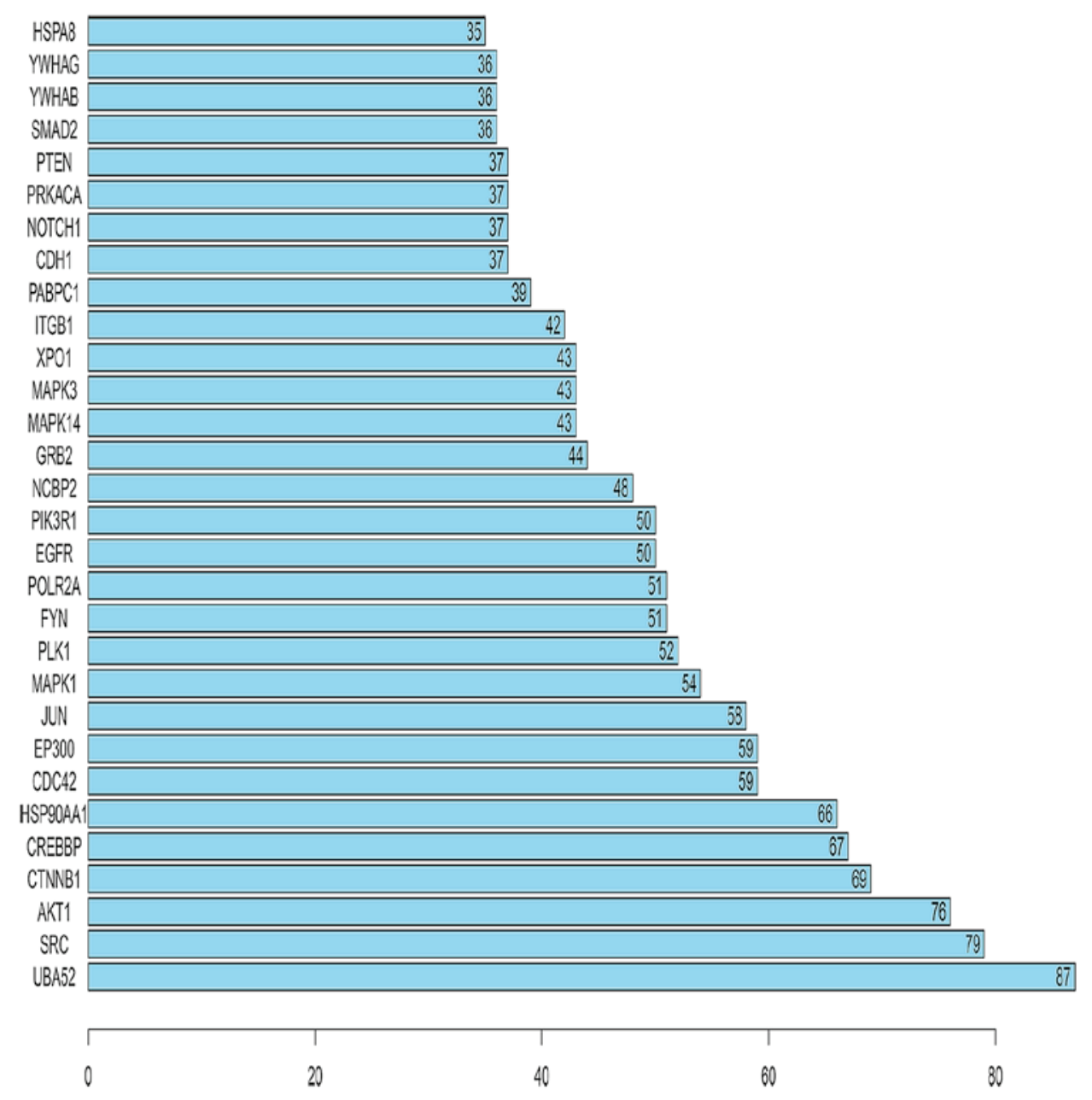

Figure 6. List of the top 30 genes of the protein-protein interaction network in order of connectivity.

For instance, the interaction data from the Starbase database and miRanda algorithm have been used to generate a global triple network based on the ceRNA theory that the lncRNA and mRNA shared the same miRNA (23). Another study has 
A
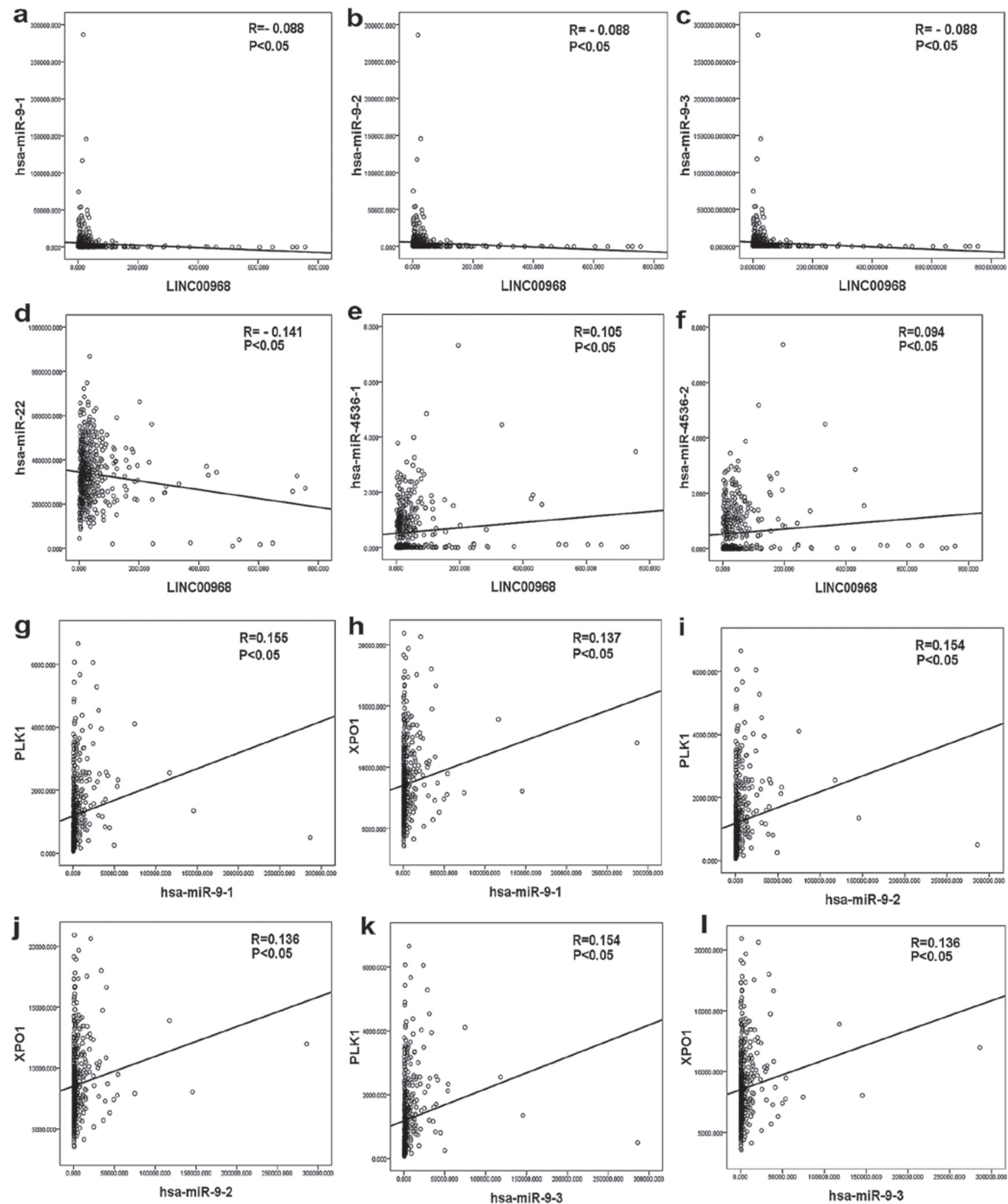

Figure 7. Correlation analysis among LINC00968, three miRNAs and two hub genes in the Cancer Genome Atlas. (A-a-f) The correlation between LINC00968 and the three miRNAs, and (A-g-l) the correlation between three miRNAs and the two hub genes. miRNA, microRNA.

shown that C032469 is able to regulate human telomerase reverse transcriptase expression by binding to miR-1207-5p in gastric cancer (24). These studies provide an approach for understanding the connection between IncRNAs, miRNAs and mRNAs in the progression and development of lung cancer. Therefore, it was necessary to construct an IncRNAmiRNA-mRNA regulatory network of LINC00968 in the present study. 
B
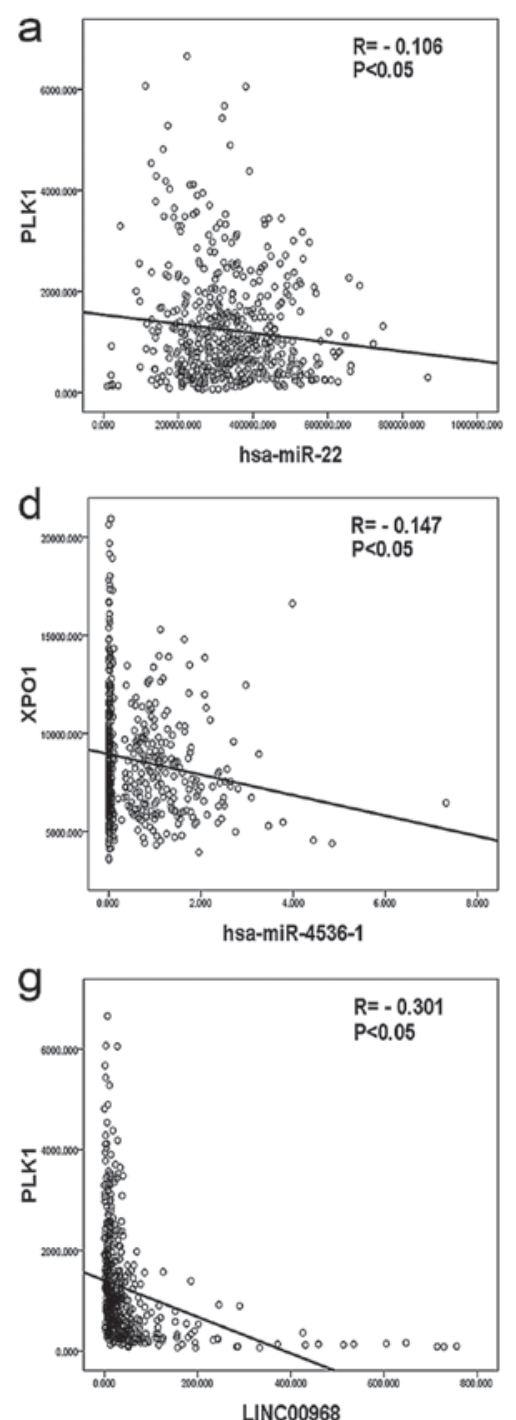
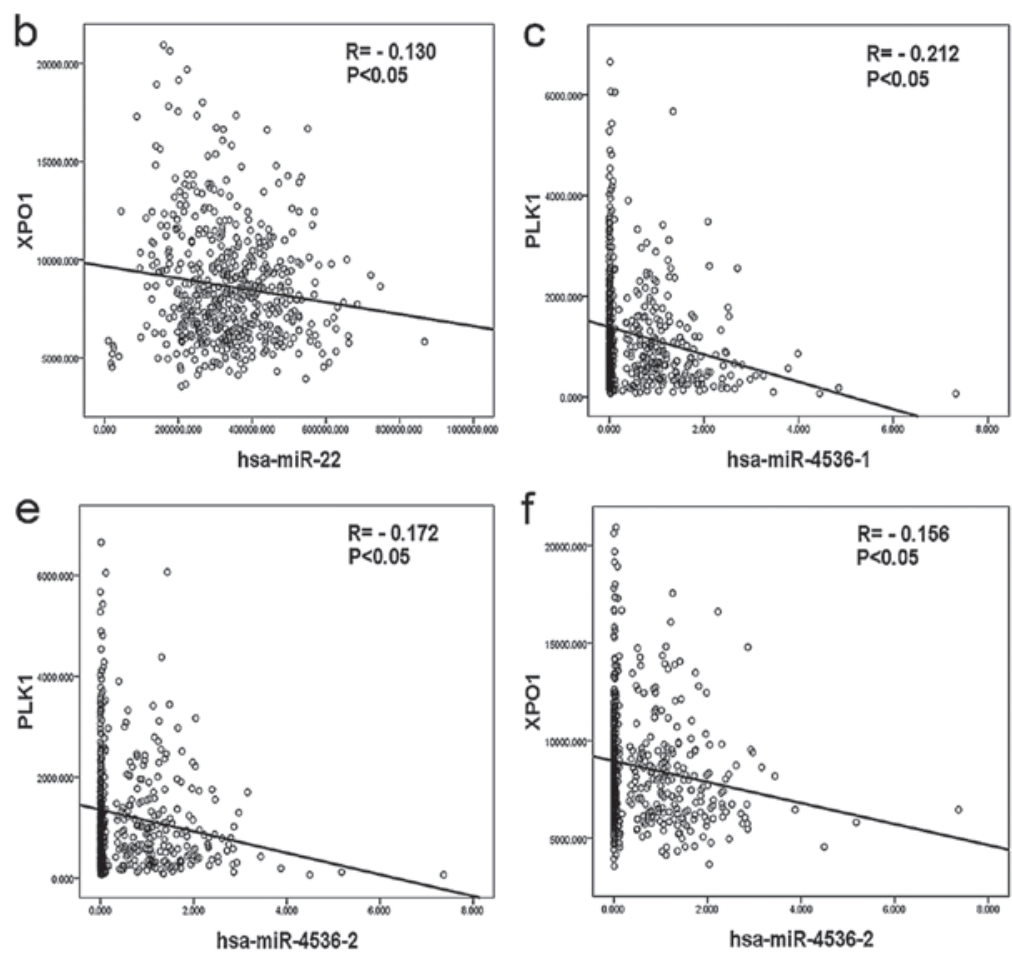

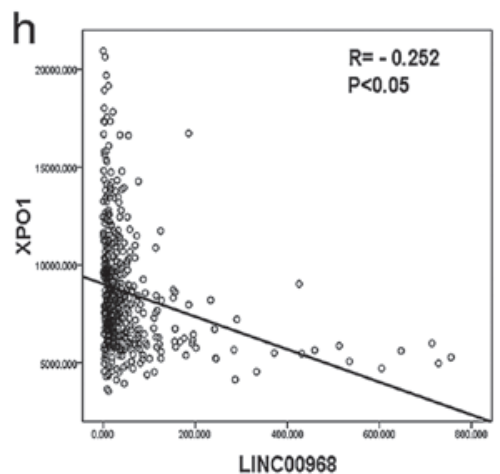

Figure 7. Continued. (B-a-f) The correlation between three miRNAs and the two hub genes, and (B-g-h) the correlation between LINC00968 and the two hub genes. miRNA, microRNA

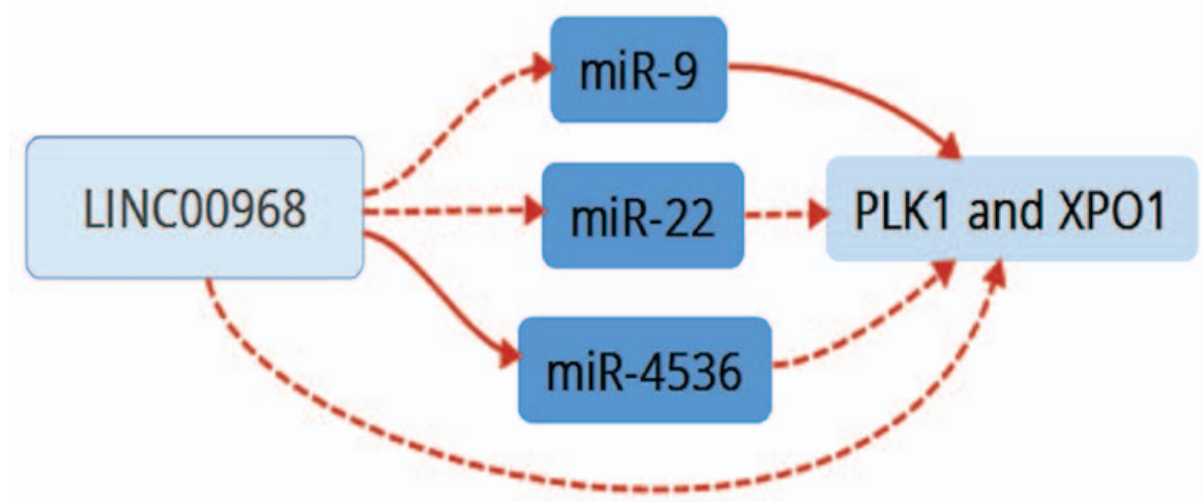

Figure 8. The lncRNA-miRNA-mRNA regulatory network was validated in lung adenocarcinoma patients in the Cancer Genome Atlas database. Solid lines represent a positive regulatory role, and dotted lines a negative regulatory role. PLK1, polo-like kinase 1; XPO1, exportin-1; lncRNA, long non-coding RNA; miRNA, microRNA.

The overexpression of LINC00968 in A549 cells induced a variation of the miRNA profile that was detected using an miRNA microarray. The results of the miRNA microarray analysis indicated that certain interactions exist between LINC00968 and five DEMs, namely miR-9-3p, miR-22-5p, miR-668-3p, miR-3675-3p and miR-4536-3p. Furthermore, by 
integrating predicted target genes and validated target genes of the five DEMs, 1,888 prospective target genes were obtained for further analysis.

GO analysis subsequently revealed that the five DEMs participated in a variety of biological processes potentially important to lung cancer progression, in the categories of biological process, cellular component and molecular function. Intracellular transport, organelle lumen and nucleotide binding were selected as representatives of the three major categories, respectively. Intracellular transport is of critical importance for a variety of life functions and is tightly associated with certain serious diseases, such as myocardial and neurodegenerative diseases and renal cancer (25-27). Studies have indicated that intracellular transport not only regulates lung cancer cell growth (28) but also regulates the intracellular levels of anticancer drugs (29). Organelles mainly include mitochondria, endoplasmic reticulum, centrosome and ribosomes, which maintain the normal structure and functions of cells. Results of previous studies suggest that mitochondria and ribosome act as key regulators in A549 lung cancer cells $(30,31)$. With regard to nucleotide binding, lncRNAs and miRNAs may bind to specific molecules: the lncRNA HOX transcript antisense intergenic RNA has been indicated to regulate the cell biological function of NSCLC through binding to hypoxia-inducible factor-1 $\alpha$ (32), and miR-486-5p may downregulate cyclin-dependent kinase 4 expression to inhibit the development of NSCLC (33). These results indicate that nucleotide binding may serve vital roles in the progression of lung cancer.

KEGG pathway analysis determined that these five DEMs participate in adherens junction and focal adhesion as these were the two most significantly enriched pathways. Adherens junctions maintain cell-cell adhesion and ensure the normal transmission of cellular signals. $\beta$-catenin and E-cadherin as core structural components of adherens junctions participate in the regulation of lung cancer $(34,35)$. Focal adhesions, highly regulated multi-protein complexes, are critical in the regulation of a number of pathological processes, such as the progression of lung cancer $(36,37)$. Under normal circumstances, adherens junction and focal adhesion are necessary for the maintenance of homeostasis (38-40). Therefore, their dysregulation in cancer cells may be closely associated with the development and progression of lung cancer.

The results of the GO and KEGG analyses suggested that LINC00968 may function as a regulator in lung cancer. Thus, an original network of LINC00968, 5 DEMs and 1,888 target genes was constructed. In addition, a PPI network of the 1,888 target genes was generated. Based on the connectivity of genes in the PPI network, the top 30 hub genes were obtained. Additionally, by correlation analysis of 18 of the top 30 hub genes with miR-9, miR-22 and miR-4536 in TCGA, two genes, namely $P L K 1$ and $X P O 1$, were found to be co-associated with miR-9, miR-22 and miR-4536. Thus, the three miRNAs and the two genes were chosen for continued investigation via in-depth studies, and an IncRNA-miRNA-mRNA network of LINC00968 validated in TCGA was constructed.

The three independent miRNAs miR-9-1, miR-9-2 and miR-9-3 are transcription products of miR-9 involved in tumor growth (41). miR-9 has shown the ability to enhance the effect of anticancer drugs in NSCLC (42) and acts as an important regulator in the evolution and progression of NSCLC (43).
Similarly, studies have shown that miR-22 not only acts as a novel biomarker for NSCLC (44), but also inhibits tumor growth and metastasis in lung cancer (45). Unfortunately, the regulatory mechanism of miR-4536 in lung cancer has not been reported; however, the common downstream target genes $P L K 1$ and XPOI of these three miRNAs serve important roles in carcinogenesis.

PLK1 regulates the development of numerous cancers by participating in the mitotic process. Previous evidence suggests that tumor progression is inhibited by the targeting of PLK1 $(46,47)$. In addition, XPO1 is a nuclear exporter that mediates the nuclear export of multiple tumor suppressors (48). Kim et al (49) discovered that the inhibition of XPOI was a promising therapeutic strategy for a cohort of patients with lung cancer.

These studies suggest that the three miRNAs and the two genes exert important influences on the regulation of lung cancer. Therefore, the network comprising LINC00968, the three miRNAs (miR-9, miR-22 and miR-4536) and the two hub genes (PLK1 and XPO1) validated in the TCGA database may be a potential regulatory mechanism with vital roles in the progression and prognosis of lung cancer. However, LINC00968 is a novel lncRNA that has not been reported previously, the precise functions of which will be the subject of subsequent studies by the present research team. The regulatory mechanisms of LINC00968 will also be analyzed.

\section{Acknowledgements}

The present study was supported by Guangxi Key Project of Science and Technology (grant no. 1598012-30), the Fund of the Guangxi Provincial Health Bureau Scientific Research Project (grant no. Z2013201), the Fund of the National Natural Science Foundation of China (grant nos. NSFC81660488, NSFC81360327 and NSFC81560469), and the Natural Science Foundation of Guangxi, China (grant no. 2015GXNSFCA139009).

\section{References}

1. Torre LA, Bray F, Siegel RL, Ferlay J,Lortet-Tieulent J and Jemal A: Global cancer statistics, 2012. CA Cancer J Clin 65: 87-108, 2015.

2. Torre LA, Siegel RL and Jemal A: Lung Cancer Statistics. Adv Exp Med Biol 893: 1-19, 2016.

3. Chen Z, Fillmore CM, Hammerman PS, Kim CF and Wong KK: Non-small-cell lung cancers: A heterogeneous set of diseases. Nat Rev Cancer 14: 535-546, 2014.

4. Zhou M, Li J, Li C, Guo L, Wang X, He Q, Fu Y and Zhang Z: Tertiary amine mediated targeted therapy against metastatic lung cancer. J Control Release 241: 81-93, 2016.

5. Khandelwal A, Bacolla A, Vasquez KM and Jain A: Long non-coding RNA: A new paradigm for lung cancer. Mol Carcinog 54: $1235-1251,2015$.

6. Castellano JJ, Navarro A, Viñolas N, Marrades RM, Moises J, Cordeiro A, Saco A, Muñoz C, Fuster D, Molins L, Ramirez J and Monzo M: LincRNA-p21 impacts prognosis in resected non-small cell lung cancer patients through angiogenesis regulation. J Thorac Oncol 11: 2173-2182, 2016.

7. Chang TH, Tsai MF, Gow CH, Wu SG, Liu YN, Chang YL, Yu SL, Tsai HC, Lin SW, Chen YW, et al: Upregulation of microRNA-137 expression by Slug promotes tumor invasion and metastasis of non-small cell lung cancer cells through suppression of TFAP2C. Cancer Lett 402: 190-202, 2017.

8. Bonasio R and Shiekhattar R: Regulation of transcription by long noncoding RNAs. Annu Rev Genet 48: 433-455, 2014.

9. Duval M, Cossart P and Lebreton A: Mammalian microRNAs and long noncoding RNAs in the host-bacterial pathogen crosstalk. Semin Cell Dev Biol 65: 11-19, 2016. 
10. Yuan JH, Yang F, Wang F, Ma JZ, Guo YJ, Tao QF, Liu F, Pan W, Wang TT, Zhou CC, et al: A long noncoding RNA activated by TGF- $\beta$ promotes the invasion-metastasis cascade in hepatocellular carcinoma. Cancer Cell 25: 666-681, 2014.

11. Shi X, Sun M, Wu Y, Yao Y, Liu H, Wu G, Yuan D and Song Y: Post-transcriptional regulation of long noncoding RNAs in cancer. Tumour Biol 36: 503-513, 2015.

12. Zhang $\mathrm{H}$ and $\mathrm{Zhu} \mathrm{JK}$ : Emerging roles of RNA processing factors in regulating long non-coding RNAs. RNA Biol 11: 793-797, 2014.

13. Guz M, Rivero-Müller A, Okoń E, Stenzel-Bembenek A, Polberg K, Słomka M and Stepulak A: MicroRNAs-role in lung cancer. Dis Markers 2014: 218169, 2014.

14. Valinezhad Orang A, Safaralizadeh R and KazemzadehBavili M: Mechanisms of miRNA-Mediated Gene Regulation from Common Downregulation to mRNA-Specific Upregulation. Int J Genomics 2014: 970607, 2014

15. Liang WC, Fu WM, Wong CW, Wang Y, Wang WM, Hu GX, Zhang L, Xiao LJ, Wan DC, Zhang JF, et al: The lncRNA H19 promotes epithelial to mesenchymal transition by functioning as miRNA sponges in colorectal cancer. Oncotarget 6: 22513-22525, 2015.

16. Liz J and Esteller M: lncRNAs and microRNAs with a role in cancer development. Biochim Biophys Acta 1859: 169-176, 2016.

17. Ye S, Yang L, Zhao X, Song W, Wang W and Zheng S: Bioinformatics method to predict two regulation mechanism: TF-miRNA-mRNA and lncRNA-miRNA-mRNA in pancreatic cancer. Cell Biochem Biophys 70: 1849-1858, 2014.

18. Zhang J, Fan D, Jian Z, Chen GG and Lai PB: Cancer specific long noncoding RNAs show differential expression patterns and competing endogenous RNA potential in hepatocellular carcinoma. PLoS One 10: e0141042, 2015.

19. Yang J, Lin J, Liu T, Chen T, Pan S, Huang W and Li S: Analysis of lncRNA expression profiles in non-small cell lung cancers (NSCLC) and their clinical subtypes. Lung Cancer 85: 110-115, 2014.

20. Kanehisa M, Sato Y, Kawashima M, Furumichi M and Tanabe M: KEGG as a reference resource for gene and protein annotation. Nucleic Acids Res 44: D457-D462, 2016.

21. Czerwinska U, Calzone L, Barillot E and Zinovyev A: DeDaL: Cytoscape 3 app for producing and morphing data-driven and structure-driven network layouts. BMC Syst Biol 9: 46, 2015.

22. Vencken SF, Greene CM and McKiernan PJ: Non-coding RNA as lung disease biomarkers. Thorax 70: 501-503, 2015.

23. Song C, Zhang J, Liu Y, Pan H, Qi HP, Cao YG, Zhao JM, Li S, Guo J, Sun HL, et al: Construction and analysis of cardiac hypertrophy-associated lncRNA-mRNA network based on competitive endogenous RNA reveal functional lncRNAs in cardiac hypertrophy. Oncotarget 7: 10827-10840, 2016.

24. Lü MH, Tang B, Zeng S, Hu CJ, Xie R, Wu YY, Wang SM, He FT and Yang SM: Long noncoding RNA BC032469, a novel competing endogenous RNA, upregulates hTERT expression by sponging miR-1207-5p and promotes proliferation in gastric cancer. Oncogene 35: 3524-3534, 2016.

25. Frismantiene A, Kyriakakis E, Dasen B, Erne P, Resink TJ and Philippova M: Actin cytoskeleton regulates functional anchorage-migration switch during $\mathrm{T}$-cadherin-induced phenotype modulation of vascular smooth muscle cells. Cell Adh Migr: 1-17, 2017.

26. Pluskota E, Bledzka KM, Bialkowska K, Szpak D, Soloviev DA, Jones SV, Verbovetskiy D and Plow EF: Kindlin-2 interacts with endothelial adherens junctions to support vascular barrier integrity. J Physiol: Aug 11, 2017 (Epub ahead of print).

27. Kleinschmidt EG and Schlaepfer DD: Focal adhesion kinase signaling in unexpected places. Curr Opin Cell Biol 45: 24-30, 2017.

28. Song S, Jacobson KN, McDermott KM, Reddy SP, Cress AE, Tang H, Dudek SM, Black SM, Garcia JG, Makino A, et al: ATP promotes cell survival via regulation of cytosolic $\left[\mathrm{Ca}^{2+}\right]$ and Bcl-2/Bax ratio in lung cancer cells. Am J Physiol Cell Physiol 310: C99-C114, 2016.

29. Galetti M, Petronini PG, Fumarola C, Cretella D, La Monica S, Bonelli M, Cavazzoni A, Saccani F, Caffarra C, Andreoli R, et al: Effect of ABCG2/BCRP expression on efflux and uptake of gefitinib in NSCLC cell lines. PLoS One 10: e0141795, 2015.

30. Holandino C, Teixeira CA, de Oliveira FA, Barbosa GM, Siqueira CM, Messeder DJ, de Aguiar FS, da Veiga VF, Girard-Dias W, Miranda K, et al: Direct electric current treatment modifies mitochondrial function and lipid body content in the A549 cancer cell line. Bioelectrochemistry 111: 83-92, 2016.
31. Kim BG, Kwon HY, Sohn EJ, Hwang S, Kwon OS and Kim SH: Activation of caspases and inhibition of ribosome biogenesis mediate antitumor activity of Chijongdan in A549 non-small lung cancer cells. BMC Complement Altern Med 14: 420, 2014.

32. Zhou C, Ye L, Jiang C, Bai J, Chi Y and Zhang H: Long noncoding RNA HOTAIR, a hypoxia-inducible factor- $1 \alpha$ activated driver of malignancy, enhances hypoxic cancer cell proliferation, migration, and invasion in non-small cell lung cancer. Tumour Biol 36: 9179-9188, 2015.

33. Shao Y, Shen YQ, Li YL, Liang C, Zhang BJ, Lu SD, He YY, Wang P, Sun QL, Jin YX, et al: Direct repression of the oncogene CDK4 by the tumor suppressor miR-486-5p in non-small cell lung cancer. Oncotarget 7: 34011-34021, 2016.

34. Dong S, Khoo A, Wei J, Bowser RK, Weathington NM, Xiao S, Zhang L, Ma H, Zhao Y and Zhao J: Serum starvation regulates E-cadherin upregulation via activation of c-Src in non-smallcell lung cancer A549 cells. Am J Physiol Cell Physiol 307: C893-C899, 2014.

35. Xu X, Kim JE, Sun PL, Yoo SB, Kim H, Jin Y and Chung JH: Immunohistochemical demonstration of alteration of $\beta$-catenin during tumor metastasis by different mechanisms according to histology in lung cancer. Exp Ther Med 9: 311-318, 2015.

36. Bennett DT, Reece TB, Foley LS, Sjoberg A, Meng X, Fullerton DA and Weyant MJ: C-terminal tensin-like protein mediates invasion of human lung cancer cells and is regulated by signal transducer and activator of transcription 3. J Thorac Cardiovasc Surg 149: 369-375, 2015.

37. Lin TY and Hsu HY: Ling Zhi-8 reduces lung cancer mobility and metastasis through disruption of focal adhesion and induction of MDM2-mediated Slug degradation. Cancer Lett 375: 340-348, 2016.

38. Colman MA, Pinali C, Trafford AW, Zhang $\mathrm{H}$ and Kitmitto A: A computational model of spatio-temporal cardiac intracellular calcium handling with realistic structure and spatial flux distribution from sarcoplasmic reticulum and t-tubule reconstructions. PLoS Comput Biol 13: e1005714, 2017.

39. Mukherjee R, Majumder P and Chakrabarti O: MGRN1 mediated ubiquitination of $\alpha$-tubulin regulates microtubule dynamics and intracellular transport. Traffic: Sep 13, 2017 (Epub ahead of print).

40. Yang Q, Wang Y, Yang Q, Gao Y, Duan X, Fu Q, Chu C, Pan X, Cui X and Sun Y: Cuprous oxide nanoparticles trigger ER stressinduced apoptosis by regulating copper trafficking and overcoming resistance to sunitinib therapy in renal cancer. Biomaterials 146: 72-85, 2017.

41. Yuva-Aydemir Y, Simkin A, Gascon E and Gao FB: MicroRNA-9: Functional evolution of a conserved small regulatory RNA. RNA Biol 8: 557-564, 2011.

42. Chen X, Zhu L, Ma Z, Sun G, Luo X, Li M, Zhai S, Li P and Wang X: Oncogenic miR-9 is a target of erlotinib in NSCLCs. Sci Rep 5: 17031, 2015.

43. Mitra R, Edmonds MD, Sun J, Zhao M, Yu H, Eischen CM and Zhao Z: Reproducible combinatorial regulatory networks elucidate novel oncogenic microRNAs in non-small cell lung cancer. RNA 20: 1356-1368, 2014.

44. Xu C, Zheng Y, Lian D, Ye S, Yang J and Zeng Z: Analysis of microRNA expression profile identifies novel biomarkers for non-small cell lung cancer. Tumori 101: 104-110, 2015.

45. Xin M, Qiao Z, Li J, Liu J, Song S, Zhao X, Miao P, Tang T, Wang L, Liu W, et al: miR-22 inhibits tumor growth and metastasis by targeting ATP citrate lyase: Evidence in osteosarcoma, prostate cancer, cervical cancer and lung cancer. Oncotarget 7: 44252-44265, 2016.

46. Wang XH, Lu Y, Liang JJ, Cao JX, Jin YQ, An GS, Ni JH, Jia HT and Li SY: MiR-509-3-5p causes aberrant mitosis and antiproliferative effect by suppression of PLK1 in human lung cancer A549 cells. Biochem Biophys Res Commun 478: 676-682, 2016.

47. Xu C, Li S, Chen T, Hu H, Ding C, Xu Z, Chen J, Liu Z, Lei Z, Zhang HT, et al: miR-296-5p suppresses cell viability by directly targeting PLK1 in non-small cell lung cancer. Oncol Rep 35: 497-503, 2016.

48. Chen Y, Camacho C, Silvers TR, Razak AR, Gabrail NY, Gerecitano JF, Kalir E, Pereira E, Evans BR, Ramus SJ, et al: Inhibition of the nuclear export receptor XPO1 as a therapeutic target for platinum resistant ovarian cancer. Clin Cancer Res 23: 1552-1563, 2016.

49. Kim J, McMillan E, Kim HS, Venkateswaran N, Makkar G, Rodriguez-Canales J, Villalobos P, Neggers JE, Mendiratta S, Wei S, et al: XPO1-dependent nuclear export is a druggable vulnerability in KRAS-mutant lung cancer. Nature 538: 114-117, 2016. 